\title{
Neighborhood Effects on Food Consumption
}

\author{
Tammy Leonard ${ }^{\mathrm{a} *}$, Caitlin McKillop ${ }^{\mathrm{a}}$, Jo Ann Carson ${ }^{\mathrm{b}}$, and Kerem Shuval ${ }^{\mathrm{c}}$
}

\author{
*Corresponding Author: Tammy Leonard, 800 W. Campbell Rd, GR31, Richardson, TX \\ 75080; 972-883-2970; Leonard@utdallas.edu \\ ${ }^{a}$ University of Texas at Dallas, School of Economic, Political and Policy Sciences, Economics \\ Department, Dallas, Texas. \\ ${ }^{\mathrm{b}}$ Department of Clinical Nutrition, The University of Texas Southwestern Medical Center, \\ Dallas, TX, USA \\ ${ }^{\mathrm{c}}$ Kerem Shuval, American Cancer Society, Intramural Research Department, Economics and \\ Health Policy Research Program, Atlanta, Georgia
}

Acknowledgements: We are grateful for the helpful comments of Dr. James C. Murdoch, Dr. Rodney Andrews, participants in the University of Texas at Dallas Brown Bag Seminar Series and participants at the North American Regional Science Association Annual Meeting.

\footnotetext{
$\underline{\text { Abstract }}$

Food consumption behavior is likely a result of environmental stimuli, access, and personal preferences, making policy aimed at increasing the nutritional content of food consumption challenging. We examine the dual role of the social and physical neighborhood environment as they relate to the eating behaviors of residents of a low-income minority urban neighborhood. We find that both proximity to different types of food sources (a characteristic of the physical neighborhood environment) and dietary intake of neighbors (a characteristic of the neighborhood's social environment) are related to dietary intake. The relationships are most robust for fruits and vegetables consumption. Proximity to fast food sources is related to less fruits and vegetables consumption while the opposite is found for individuals residing closer to fresh food sources. Additionally, individuals whose neighbors report increased fruits and vegetables intake also report higher fruits and vegetables consumption, while controlling for proximity to food sources. Instrumental variable and quasi-experimental robustness checks suggest that correlation in neighbors' fruits and vegetables consumption is likely due to social interactions among neighboring residents. The results elucidate important inter-relationships between access and social norms that influence dietary behavior.
} 
JEL Codes: H51, H31, I14, I15

Key words: Neighborhood effects; Nutrition; Spatial econometrics; Social Influence Number Tables: 7

Number Figures: 1 


\section{Introduction}

Poor nutrition increases the risk of obesity, cancer and cardiovascular disease (Block, Patterson et al. 1992; Hung, Joshipura et al. 2004; Hill 2006; Getz and Reardon 2007; Satija and Hu 2012; Wang, Manson et al. 2012; Jung, Spiegelman et al. 2013; Threapleton, Greenwood et al. 2013). The cost of increased obesity is significant. Compared to normal weight individuals, obese individuals will experience 14-25\% more physician visits per year, 6 times more pharmacy dispenses for diabetes medication, and 3.4 times more pharmacy dispenses for cardiovascular medications (Finkelstein, Strombotne et al. 2010). Additionally, studies have found that overweight and obese individuals are valued less in labor markets as evidenced by lower wages (Wada and Tekin 2010). The paramount importance of adhering to a healthful diet to improve health outcomes and reduce subsequent medical costs has led economists, public health researchers, and policy advocates to study environmental factors impacting dietary consumption (US House of Representatives Select Committee on Hunger 1987; US House of Representatives Select Committee on Hunger 1992; Turrell 1996). The United States Department of Agriculture estimates that only 2.2 percent of the U.S. population live further than a mile from a major supermarket or grocery store (Ver Ploeg, Breneman et al. 2009). However, aggregate measures of food access often fail to account for many factors that impact food accessibility and are often impeded by challenges associated with obtaining timely food source data. Policy focused on decreasing the distance to grocery stores alone may not be effective in addressing nutrition disparities. Additionally, behavioral economists, sociologists, and social psychologists would contend that factors such as social norms jointly influence the food availability in a community and the food choices made by community residents (Elster 1989; Akerlof 1997; Azar 2004; Ioannides 2012). We analyzed data from a low-income minority community to better understand the social and access-related correlates of food consumption. 
To date a significant gap remains in our understanding of how the physical and social environments combine to influence nutrition behavior (Townshend and Lake 2009). We bridge this gap by examining a unique dataset that includes geographically referenced (e.g. home addresses) nutritional intake of survey respondents and information about the location of all commercial and the largest non-profit food sources in a low-income minority food desert neighborhood. In our analysis, we apply concepts from the rich literature on neighborhood effects (e.g. (Manski 1993; Dietz 2002; Durlauf 2004)) to the research question. Our research question has primarily been examined by public health researchers, and the approaches used have yet to sufficiently incorporate the full set of geographic, social and individual level determinants impacting nutrition behavior. Specifically, our research contributes to the extant literature by examining the role of neighbors' food consumption on individuals' dietary choices.

\section{Background}

Food expenditure data indicate that habits play a significant role in food purchasing behavior (Naik and Moore 1996; Zhen, Wohlgenant et al. 2011). If policy initiatives are going to promote changes in nutrition behaviors, they must effectively overcome the inertia created by habitual behaviors. In a longitudinal study, habitual food consumption was found to account for 50 percent of all food expenditures (Naik and Moore 1996).

The determinants of nutrition behavior may be considered from the perspective of identifying key factors influencing nutrition habits. Observed habitual behavior may be rooted in social norms, peer effects, or factors related to food cost or availability (Elster 1989). One reason habits may develop and strongly influence dietary intake is that food environments, particularly for low-income consumers, often constitute a very limited choice-set due to high prices and limited selection. Additionally, social factors may influence eating habits through a preference 
for conformity and/or costs imposed by going against social norms. Social factors may also reinforce inertia as long as the peer group or norm remains stable. Finally, individual specific tastes, preferences and demographic characteristics are related to dietary intake and are relatively stable — or at least do not rapidly change.

\subsection{Food Deserts and Access to Affordable Nutritious Food}

Disparities in access to healthy food sources exist for minorities and low-income households (Zenk, Schulz et al. 2005; Powell, Slater et al. 2007) who also have a higher prevalence of obesity (Ford, Giles et al. 2002; Black and Macinko 2008). However, a review of the literature linking the availability of neighborhood food sources and obesity revealed no consistent causal relationship between food resources and health disparities (Black and Macinko 2008). Some studies have linked the presence of large chain grocers to decreased body mass index (BMI) (Morland, Diez Roux et al. 2006; Moore, Diez Roux et al. 2008; Morland and Evenson 2009), while others have found the opposite, no association, or associations only for specific subpopulations (Wang, Kim et al. 2007; Chen, Florax et al. 2010; An and Sturm 2012; Wen and Maloney 2013). The results for proximity to unhealthy food sources (such as convenience stores or fast food restaurants) (Burdette and Whitaker 2004; Maddock 2004; Simmons, McKenzie et al. 2005; Morland and Evenson 2009) and the relationship between neighborhood context and BMI (Do, Dubowitz et al. 2007; Wen and Maloney 2013) are similarly mixed.

One explanation for the lack of consensus regarding the relationship between access and nutrition-related health outcomes may be the inability to model neighborhood contexts that shape behavior. For households without private vehicles, the ability to secure alternative travel arrangements was a far greater factor in shopping decisions than distance to food sources (Coveney and O'Dwyer 2009); and individuals who walk to food sources have been shown to 
have relatively poorer diets (Morland et al., 2002; White et al., 2003; Wrigley, 2002). Chen et al. (Chen, Florax et al. 2010) found a negative relationship between prevalence of chain grocers and BMI only for low-income neighborhoods. In one of the only studies examining an exogenous change in food access, Wrigley et al. (Wrigley, Warm et al. 2003) studied the impact of opening a new chain grocery store in a food desert neighborhood in the United Kingdom. They found that improved access was associated with better nutrition for only certain subgroups within the neighborhood.

Another factor that must be taken into consideration when assessing relationships between the food environment and food consumption is consumer demand. Consumer demand may drive location choices of commercial food sources. Individuals with above average BMI and below average nutrition preferences may sort into neighborhoods with fewer nutritious food resources. However, since large chain grocers generally provide both healthy and non-healthy food, it is unlikely that these factors alone would support associations between lack of commercial food resources and poor nutrition and/or weight gain. Alternately, low-income neighborhoods may not provide sufficient consumer demand for commercial food sources because non-profit food sources are also available. These demand-driven explanations for the spatial distribution of commercial food sources may contribute to the heterogeneity in associations between food source location and health/nutrition outcomes. A recent review of the food desert literature concluded that there is a need for additional research focusing on the causal role of food access disparities on dietary intake. This work acknowledges the need to disentangle the complex supply/demand relationships that shape the food access landscape (Walker, Keane et al. 2010).

\subsection{Social Factors which Influence Nutrition Choices}


Studies examining food access have not accounted for social influences (Ichiro, Daniel et al. 2004; Viswanath 2006; Viswanath and Bond 2007), which may be an important aspect of neighborhood context that might explain the variability in results in the food access literature. Other consumption behaviors, such as consumption of environmentally-conscious products, has been associated with peers' consumption behavior (Starr 2009). Focusing specifically on dietary consumption, evidence is also available. In a large qualitative study of a US multi-ethnic population, African Americans reported that a diet rich in saturated fat served during church functions was a key impediment to a healthful diet (Yeh, Ickes et al. 2008). A review of the determinants of child nutrition also revealed important family and social correlates (Patrick and Nicklas 2005), and recent studies observed familial influences on vegetable consumption patterns among African American parent-teen dyads (Zhylyevskyy, Jensen et al. 2012). In addition, experimental economic evidence has found reciprocal relationships between peers with regards to restaurant selection and food choices (Keane, Lafky et al. 2012). Further, being part of a social group where other members recently gained weight has been related to an individual's adoption of obesity-related peer behaviors (Eisenberg and Quinn 2006) and likelihood of obesity (Christakis and Fowler 2007). However, much controversy remains regarding the causal nature of these associations (Cohen-Cole and Fletcher 2008; Cohen-Cole and Fletcher 2008; Sainsbury 2008; Lyons 2011; Noel and Nyhan 2011; Shalizi and Thomas 2011).

Social influence may be reinforced by individual characteristics that are often shared among social peers and residents of similar neighborhoods. For example, first, income is related to differences in food purchasing behavior due to cost concerns (Glanz, Basil et al. 1998; Turrell and Kavanagh 2005); and second, cultural values and traditions more effectively establish and reinforce social norms related to nutrition in neighborhoods that are more homogeneous in terms 
of race and ethnicity (Habyarimana, Humphreys et al. 2007). Taken together, these factors suggest that preferences or constraints related to individual race/ethnicity and socioeconomic status might be reinforced within peer networks. These factors may be key moderators of the social and access correlates of nutrition behavior.

To the extent that social norms or peer influence is related to nutrition decisions, these factors may be leveraged to support healthier behavior. In theoretical work, social norms which produce undesirable outcomes (e.g. a norm for eating fast food) may be more amenable to policy focused on changing the norm itself, rather than fiscal policy (e.g. taxes) (Kallbekken, Westskog et al. 2010). Additionally, considerable work has been done to understand malleability of social norms by considering the different types of actors within a social system (e.g. leaders and followers) (Lopez-Perez 2009).

\section{Methods}

\subsection{Econometric Model}

Our econometric model is based on the theoretical foundations of the human capital model of the demand for health (Grossman 1972; Grossman 2000). In the initial version of the Grossman model, education was proposed as the primary exogenous variable that affects the efficiency of health production. The list of potential modifiers that impact health production efficiency was later expanded to include "non-cognitive" skills (Chiteji 2010) and "sociocultural" factors (Huston and Finke 2003). We add to this list, characteristics of the physical and social environment that may impact the efficiency of health production. Therefore, we propose that investment in health is achieved through a household production function defined at every time, $\mathrm{t}$, as:

$$
I_{t}=I_{t}\left(M_{t}, T H_{t} ; E, S, N_{t}, D_{t}\right)
$$


where $M_{t}$ is a vector of inputs. We are focused on the food consumption (c) health input. $T H_{t}$ is time devoted to health improving activities and is endogenous. $E$ is education, $S$ are individual socio-cultural characteristics; $N_{t}$ are characteristics of the individual's social environment and $D_{t}$ are characteristics of the individual's physical environment. The characteristics of an individual's social environment may improve the efficiency of health production by making it easier to adopt healthy behaviors both in terms of social costs (e.g. difficulty going against social norms and not consuming unhealthy food at social gatherings) and in terms of real costs (e.g. friends who prepare healthy meals may share their expertise lowering the time-cost associated with learning to cook). Characteristics of an individual's physical environment improve efficiency of health production primarily from lowering the costs associated with accessing health inputs. One may also consider the physical environment's negative role from the perspective of lowering the costs of unhealthy inputs.

We then follow the work of Grossman (Grossman 1972; Grossman 2000), and assert that household production affects the stock of health capital, and consumers maximize utility subject to a budget constraint. Individuals will choose health inputs based on the efficiency factors (education, socio-cultural characteristics, and characteristics of the physical and social environment) and the price of health inputs.

We, therefore, propose a cross-sectional, multivariate model for food consumption:

$$
c=\rho W c+\alpha E+\beta S+\chi N+\delta D+\phi P+\epsilon
$$

Food consumption, $c$, is a function of health production efficiency modifiers: individual educational attainment $(E)$, socio-cultural characteristics $(S)$, characteristics of the individual's social network--which includes both network characteristics $(N)$ and peers' food consumption 
$(\rho W c)$, the physical environment described by access to different food options $(D)$, and financial characteristics related to health input prices $(P)$.

The weights matrix, $W$, specifies the peer group relevant for each individual, where geographic proximity defines peers. Within the very low-income, low mobility sample that we examined it is plausible that neighbors are a source of social influence, particularly since $44 \%$ of the sample report all or most friends and family live in their neighborhood. Educational attainment $(E)$ was measured by the highest degree achieved. Socio-cultural characteristics included in $S$ were gender, age, marital status, presence of children in the households, whether or not the household has adequate health insurance, obesity, and self-reported health status. Obesity and self-reported health status were included because the public health literature supports the possibility that they may confound the relationship with the social and physical environment (Moore, Roux et al. 2013). However, we recognize that they are likely endogenously determined with food consumption, and do not assert the existence of any causal relationship. ${ }^{1}$ The social characteristics $(N)$ examined are the extent to which the individual's contacts exercised (a measure of positive orientation towards preventive health behaviors), whether contacts live in the same neighborhood as the respondent (a measure of the social network's geographic closure) and the interaction of these two characteristics. Average food consumption of geographically close peers $(\rho W c)$ is also a measure of the social environment. Characteristics of the physical environment included in $D$ were perceived quality of neighborhood grocery stores, and the Euclidean distance from the individual's home to the nearest fast food restaurant, commercial fresh food source, and major non-profit food pantry. Major non-profit food pantries are defined

\footnotetext{
${ }^{1}$ The results of the paper do not change materially when these variables are included/excluded and estimates of models without obesity and self-reported health status are available from the authors upon request.
} 
as charitable food providers who are members of the North Texas Food Bank, the primary charitable food distribution organization in the region. Finally, variables relating to the price of health inputs $(P)$ were income, monthly food expenditures, and home food production frequency. Table 1 provides a complete description of the variables included in the model. The model specified is a classic spatial lag model (Anselin 1988) which was estimated using maximum likelihood estimation techniques (LeSage 2012).

We must be cautious in our interpretation of the geographic peer effects observed in a cross-sectional model. Correlations in the behavior of neighbors may be attributed to three potential sources: endogenous effects, exogenous effects (also called contextual effects), and correlated effects (Manski 1993). Each of these effects is independently controlled for in (2) and non-linearity in the model allows for identification (Lee 2007; Bramoulle, Djebbari et al. 2009; Davezies, D'Haultfoeuille et al. 2009; Durlauf and Ioannides 2010). The geographic peer effects are endogenous effects. Individual decisions are endogenously related to the decisions made by one's peer group. Exogenous effects are captured in $D$ and $N$. Similar social and physical environments, which may exogenously influence nutrition behavior, influence individuals living near to each other. Correlated effects are accounted for with the individual education, sociocultural, and financial controls. One reason we may observe correlation in behavior within neighborhoods is because individuals with similar characteristics sort into similar neighborhoods.

This model applied to cross-sectional data, however, has its limitations. Rather than modeling time dependence in nutrition behavior directly (i.e. the choice to eat a high-fat fastfood meal because my friend first made this decision), the spatial lag model in (2) models the resulting equilibrium generated by time-dependent decisions made by individuals located at 
various points in space whose decisions may have been shaped by their neighbors (LeSage and Pace 2009). Estimated endogenous peer effects obtained from the cross-sectional model may result in biased inference if they are correlated with an omitted, spatially dependent variable (Corrado and Fingleton 2012). In what follows, we first estimated the cross-sectional model and then employed instrumental variables and additional data measuring neighborhood social cohesion to better understand the degree to which the estimated spatial lag term, $\rho$, is related to social influence of geographic peers.

\subsection{Data}

\subsubsection{Study Sample}

Data is derived from the second cross-sectional wave of the FairPark Study (October 2009-February 2010), a longitudinal research project studying the effects of public investment on light rail public transportation in a low-income, minority neighborhood in Dallas, Texas (Leonard, Caughy et al. 2011). This urban neighborhood has approximately 20,000 residents and the median annual income is $\$ 19,939$. Neighborhood residents are primarily African American (70 percent) and Hispanics (26 percent). The neighborhood is a 2000 -acre area comprised of 32 block-groups that fall into seven census tracts. A Geodatabase was constructed for the project, and the location and offerings of all commercial food sources was recorded. Within the neighborhood, there is one small chain grocery store, and only 20 stores that sell fresh foods such as fresh fruits or vegetables. Our numeration of fresh food sources was very broad; we included convenience stores or restaurants that offered fruit such as bananas or apples for purchase. In contrast to the availability of fresh food, there are 42 fast food sources in the neighborhood. Several retailers offered both fresh and fast foods. Figure 1 shows the distribution of study participants and neighborhood food sources. 
In total, 496 neighborhood residents provided data for the variables summarized in Table 1. Any observations that were missing data for variables used in the analysis were dropped from the sample. Most cases of missing data were a result of missing educational attainment (38 observations), detailed financial information needed to calculate per capita food expenditures (46 observations) or missing information about food consumption needed to calculate the dependent variables (18 observations). Additionally, 31 observations could not be geo-coded. The final study is based on a sample of 298 participants with the complete set of variables necessary for the analysis.

Summary statistics for each variable used in the study are shown in Table 2. Males comprised 43 percent of the sample and the average respondent's age was 44 . Seventy-seven percent of the sample had at least a high school degree. Most (93 percent) were African American. About half (47 percent) lived in households with children, but only 25 percent were married or living with a partner. The sample is of very low income, with nearly half (49 percent) living in households that made less than $\$ 10,000$ annually. Forty-one percent lacked adequate health insurance, but 71 percent reported being in good or better health. Despite the poor food landscape in the neighborhood, 37 percent of respondents reported that the assortment of grocery stores in their neighborhood was adequate. Respondents generally cooked very few meals at home; 62 percent prepared 5 or fewer meals per week. Many respondents' social networks were rooted in the neighborhood; 44 percent reported that all or most family and friends lived in their neighborhood. As expected given the low number of neighborhood grocery options, on average respondents were 33 percent closer to a fast food source than a fresh food source. The neighborhood is very low-income and the nearest large food pantry was on average as close as the nearest fast food source. 


\subsubsection{Measures}

The dependent variables were calculated from responses to the National Cancer Institute (NCI) Multifactor Screener (NCI 2000). The Multifactor Screener is comprised of a series of 16 questions regarding the type and frequency of food consumption. Based on responses to these questions and the participants' gender and age, three measures of nutritional intake were calculated: percent of energy from fat (Fat), pyramid servings of fruits and vegetables consumed (excluding French fries) (Fruit \&Vegetable), and grams of fiber consumed (Fiber). In validation studies, the correlation between the Multifactor Screener estimates of dietary intake and true intake were 0.5-0.8 (Thompson, Midthune et al. 2004). In the analysis that follows, we use the variance-adjusted values of these variables (Thompson, Midthune et al. 2005).

Obesity status (Normal Weight, Overweight, Obese) was based on the world health organization's categorization of BMI (World Health Organization 2013). BMI was computed using the standard formula $\left(\mathrm{kg} / \mathrm{m}^{2}\right)$ using objectively measured height and weight. All other variables were based on self-report. Nutrition-related perceptions and behaviors were measured based on perceptions of the adequacy of grocery stores in the neighborhood (Perceived Good Access) and the number of meals prepared at home in a typical week. The social network was characterized as "close family and friends" and respondents were asked to report about the characteristics of their network by answering a series of questions where the response choice was "all of them, more than half, fewer than half, or none". Our measure of a geographically close network (Friends in Neighborhood) indicates observations in which more than half close family and friends lived in the neighborhood. We used whether or not more than half of the respondent's friends and family exercised on a regular basis (Friends Exercise) as an indicator of the health consciousness of the social network. Access to food sources was calculated in ArcMap using straight-line distances between the respondent's address and the location of food sources. 
The food source data was obtained through direct observation. All commercial properties in the study area and the area immediately surrounding the study area were coded to avoid any potential edge effects.

\section{Estimation and Results}

We first used Ordinary Least Squares (OLS) to estimate (2) excluding the term which measures peer effects, $\rho W c$. This allowed us to assess the impact of excluding this potentially important variable in the analysis. We estimated one model for each of the dependent variables that measures dietary intake. Next we used maximum likelihood estimation to estimate (2) including the peer effects term. Finally, we conducted sensitivity analysis to further investigate the nature and potential mechanisms behind geographic peer effects.

\subsection{Ordinary Least Squares (OLS) Results}

Estimation results and heteroskedasticity robust standard errors are displayed in Table 3. Only a few socio-cultural and financial characteristics display statistically significant estimated relationships with dietary intake. This is likely due to the homogenous low-income, minority composition of the sample. Older individuals tended to consume fewer calories from fat and fewer fruits and vegetables. Lower income and African American respondents consumed a higher percentage of calories from fat. Normal weight respondents consumed a higher proportion of fat (compared to fat consumption among obese respondents), but they also consumed more fruits and vegetables.

Individual nutrition-related perceptions and behaviors are important correlates of dietary intake. Individuals who perceived the local supply of grocery stores as adequate tended to consume more fats whereas more frequent home meal preparation was related to more fruit, vegetable and fiber consumption. 
Respondents whose social network was primarily composed of neighborhood residents consumed a higher percentage of calories from fat. This may be reflective of cultural norms within the neighborhood. However, individuals whose social network members exercised on a regular basis ate more fruits and vegetables. These results suggest that the behavioral choices of geographic peers are related to both more and less healthy decision making.

Variables measuring access to neighborhood food sources were statistically significant only in the model for fruits and vegetables. For this model, living nearer to a fresh food source was related to increased fruits and vegetables consumption while living nearer to fast food restaurants was associated with reduced fruits and vegetables consumption.

The relationships with proximity to food sources would be more meaningful if proximity was also related to utilization of the food source. Although we were unable to assess this for fast food restaurants and pantries, we did collect data regarding where participants shopped for groceries. Grocery shopping behavior was assessed by asking participants for the location of the grocery store they went to for major grocery shopping trips and the store they went to most often for smaller trips in between the major grocery trips. This data was only available for 256 of the study respondents. Sixty-four percent reported shopping at neighborhood fresh food sources. We estimated a logistic regression model with use of neighborhood fresh food sources for either major or smaller trips as the dependent variable and proximity to neighborhood fresh food sources as the key independent variable. Estimation results are presented in Table 4. Proximity to the neighborhood fresh food sources was the largest determinant of shopping at a neighborhood fresh food source.

\subsection{Geographic Peer Effects in Dietary Intake}


Next we examined the full spatial lag model indicated in (2). The robust Lagrange Multiplier tests (Florax, Folmer et al. 2003) indicated that the spatial lag model was the appropriate model for both fruits and vegetables (LM lag statistic $=9.9$ vs LM error statistic $=6.3$ ) and fat (LM lag statistic $=7.1 \mathrm{vs} \mathrm{LM} \mathrm{error} \mathrm{statistic}=6.3$ ); however, the results were inconclusive for the fiber model (LM lag statistic $=0.004$ vs LM error statistic $=0.006$ ). We based our primary analysis on a weights matrix for the " 8 nearest neighbors" of each individual. Each of the 8 nearest study participants was weighted by inverse straight-line distance, and the $W$ matrix was row-standardized. All study participants had at least one neighbor within $1 / 3$ of a mile and the farthest neighbor considered in the analysis was less than 1 mile away. The median distance between neighbors was 0.11 miles. Inverse distance weighting of neighbors allowed for the nearest neighbors to have the greatest influence as suggested by Tobler's first law of geography (Tobler 1970). Results are robust to alternative specifications of the spatial weights matrix (i.e. 6 nearest neighbors, 10 nearest neighbors and equal weighting of all nearest neighbors).

The estimation results for the spatial lag model and heteroskedasticity robust standard errors are displayed in Table 5. The coefficient on the average of geographic peers' dietary intake, $\rho$, is statistically significant only in the fruits and vegetables model: fruits and vegetables consumption of geographic peers is positively associated with an individual's fruits and vegetables consumption.

The relationships between education, financial, socio-cultural, and social and physical environment characteristics remain unchanged with only a few exceptions: age is no longer significant for any outcome, while those with a higher food budget are slightly more likely to consume a higher percentage of calories from fat and fiber. Also, the correlation between home food preparation and dietary intake is more pronounced in the spatial models: compared to the 
reference group who do not cook at home, respondents who cook 1-5 meals at home consume over a half serving more fruits and vegetables in their diet while those who cook 20 or more meals at home consume slightly over one additional serving of fruits and vegetables per day (in comparison to the reference group who do not cook at home). However, while cooking at home is related to a more healthy diet in terms of fruits and vegetables consumption, the opposite appears true when considering the percent of calories consumed from fat: more meals prepared at home is related to a higher percentage of calories from fat.

Both the OLS and spatial lag models find that respondents living nearer to fast food restaurants incorporate fewer fruits and vegetables into their diet. However, only the OLS estimation indicates that living closer to fresh food sources is associated with increased in fruits and vegetables consumption.

\subsection{Identification Checks for Geographic Peer Effects}

Thus far we have assumed the $\rho W c$ term is capturing geographic peer effects in food consumption. If geographic proximity is a proxy for social influence we expect that the influence of a respondent's eight closest neighbors will be greater than the next closest group of eight neighbors. To evaluate this we compared the fruits and vegetables model (with a weight matrix of nearest neighbors 1 through 8) to an alternative specification using the same spatial model but replacing the original weight matrix with a weight matrix containing the next set of eight neighbors (nearest neighbors 9 through 16). The coefficient of the peer effects term, $\rho$, in the alternative specification is insignificant. $^{2}$

Another concern with the estimated geographic peer effects may be characterized as an endogeneity issue. While we have referred to the estimated coefficient for the spatially weighted

\footnotetext{
${ }^{2}$ Results available from the authors upon request.
} 
fruits and vegetables consumption of geographic peers as a "peer effect" and the model defined in (2) satisfies the identification criteria for peer effects (Lee 2007; Bramoulle, Djebbari et al. 2009), the causal mechanism for the relationship is unresolved. Of particular concern is the possibility that the geographic peer effect is being driven by an omitted spatially dependent variable. This concern is similar to recent critiques regarding the proper causal interpretation of spatially lagged explanatory variables (Corrado and Fingleton 2012; Partridge, Boarnet et al. 2012). To investigate this possibility, we use instrumental variables to better understand the nature of the mechanism through which fruits and vegetables consumption of geographic peers is related to individual fruits and vegetables consumption.

For instruments, we are interested in variables related to fruits and vegetables consumption of geographic peers, but not related to the individual's specific fruits and vegetables consumption. The spatial lag of the geographic peers' education, financial, socio-cultural, and social and physical environment characteristics satisfy this condition. Neighbors' education, financial, and socio-cultural characteristics (e.g. income, race/ethnicity, education) should not influence the individual's own dietary intake unless social influences are at work. The same argument applies to neighbors' social network measures. The access measures of neighbors may influence individuals' own dietary intake without social influence if the shared food environment or some other omitted variable that similarly varies over space (e.g. commercial development, access to retail, etc.) is responsible for the observed geographic peer effects. As a further test of the validity of the instruments, we have included them as independent variables in the fruits and vegetables model and the estimated coefficients were not significant $(\mathrm{F}$-statistic $=1.28, \mathrm{p}=.1623)$. Further the spatial lag of geographic peers' demographic, network and access variables were significantly related to the average fruits and vegetables consumption of the peers. In what 
follows, we use 3 sets of instruments: (1) the full set of spatially lagged education, financial, socio-cultural, and social and physical environment characteristics variables (F-statistic $=10.18$, $\mathrm{p}=0.000) ;(2)$ only the spatially lagged education, financial, socio-cultural, and social network variables (F-statistic $=9.58, \mathrm{p}=0.000)$; and (3) only the spatially lagged physical environment (access) variables ( $\mathrm{F}$-statistic $=3.80, \mathrm{p}=0.000)$.

Table 6 presents the results for the fruits and vegetables model where the geographic peer term $(W c)$ is instrumented in each of the 3 different ways. First, we observed that the instrumented $W c$ term is statistically significant in Model 1 (when the full set of instruments was used) and Model 2 (when the spatially lagged characteristics of the people were used as instruments), but not in Model 3 (when the spatially lagged characteristics of the place were used as instruments).

The estimated results for Models 1 through 3 suggest geographic peers, or some characteristic of people in the neighborhood, is driving the relationship between geographic peers' nutrition and individual nutrition behavior; however, it can be argued, that the results do not conclusively point to a social mechanism. First, the instruments for Model 3 (those based on spatially lagged characteristics of the place) are weaker than the instruments for Models 1 and 2. One might argue that this is precisely because the geographic peer effects are less related to physical attributes of the environment, but there is also the possibility that we are missing some important aspect of the environment that would make a stronger instrument. Second, the peer effects observed in Model 2 (those based upon spatially lagged characteristics of the people) may be related to geographic sorting: individuals choose their housing location based on shared interests and characteristics. However, this is unlikely in our sample for a number of reasons. The sorting hypothesis would require individuals to sort on a very small scale. Usually we 
consider individuals to sort into neighborhoods, areas of a city, school districts or subdivisions. If the observed geographic peer effects were a result of sorting, it would require sorting on a much finer geographic scale—-sorting at the block level within a neighborhood. Also, it is unlikely that this very low-income sample has the means to freely choose their housing location. The last potential mechanism driving the geographic peer effects is actual social interactions within the neighborhood among the geographic peers.

These three competing explanations for the IV results reported in Models 1-3 are related to the critique of Gibbons \& Overman (Gibbons and Overman 2012): the crucial assumption underlying the ability to causally identify endogenous peer effects relies on knowing the proper specification of the spatial weights matrix. If we know with certainty that the spatial weights matrix, $W$, represents true social interactions, then the causal role of geographic peers supported by Models 1-3 is valid. In the absence of this definitive knowledge of spatially-based social networks, more experimental approaches that depend upon exploiting variation within the sample have been advocated (Gibbons and Overman 2012). Next, we use additional information about the neighborhood environment to exploit such variation.

We do not observe the extent to which geographic peers interact, but we do have data regarding sociability of the neighborhood. In the first wave of data collection in the neighborhood, we obtained a spatially weighted sample of 1412 individuals. Each of these individuals provided answers to two questions pertaining to geographic peer interactions: (1) the number of people outside of their household that they talk to on a daily basis when they are at their home and (2) whether they feel comfortable asking someone on the sidewalk for help carrying something to their home. The crucial element of these survey questions is that they gauged social interaction behavior near the home - the exact element of social behavior that 
would generate geographic peer effects. The answers to these questions were categorical and we used them to create two binary variables: Talk is an indicator variable for individuals who talked with 6 or more non-household members on days that they were home ${ }^{3}$; and help is an indicator variable for individuals who were always or sometimes willing to ask a passerby for help carrying something to their home. For each of the current study participants (the N=298 sample), we calculated the percentage of first wave respondents (the $\mathrm{N}=1412$ sample) within 400 meters of their home for which talk took on a value of 1 (pct_talk) and the percentage of respondents within 400 meters of their home for which help took on a value of 1 (pct_help). Pct_talk and pct_help were then normalized for our sample of 298 observations, and we stratified the sample based on the normalized values. Estimation results based on the stratified samples are presented in Table 7 . Model 4 reports the instrumental variables regression using the "people" instruments (spatially lagged demographic and network characteristics) when pct_talk is more than 0.25 standard deviations greater than the average, and Model 5 reports the same regression results for the sub-sample in which pct_talk is more than 0.25 standard deviations less than the average. Likewise, Model 5 is based on the sample for pct_help more than 0.25 standard deviations above the average, and Model 6 is based on the sample for pct_help more than 0.25 standard deviations below the average. Geographic peer effects are statistically significant only for individuals living in neighborhoods where neighbors reported talking to others (Model 4) and felt able to ask each other for help (Model 6). These results strongly imply a social mechanism for the estimated relationship between individual and geographic peer consumption of fruits and vegetables.

\section{Discussion and Conclusions}

\footnotetext{
${ }^{3}$ Response choices for the question upon which Talk is based were less than 3, 3-5, 6-10 or more than 10 . We chose 6 as the cut-point because it was the mid-point of the possible answer choices.
} 
The results highlight the role of social factors in nutrition determinants and point to a need for comprehensive solutions to improve dietary behavior of low-income individuals. However, these findings should be considered in light of the limitations of the study. First, the sample came from a single low-income neighborhood, thus impacting the generalizability and external validity of study findings to other low income minority neighborhoods. Second, we have incomplete data on the geographic peer network because network members were restricted to being in the study's sample. Additionally, we only have self-report information about the social network characteristics, and we do not know the degree to which social and geographic peer networks overlapped in the sample. Third, the distance between study participants and food sources were calculated using straight-line distance, which often underestimates the actual distance using the road network. Associations using distance measured along the road network may differ from those reported here. Fourth, beyond social and environmental factors, individual attitudes, knowledge and preferences impact dietary intake. The Socio-Ecological model emphasizes the multitude of factors affecting health behaviors on the intrapersonal, interpersonal, and community levels (National Cancer Institute 2005). While the current study takes into account aspects of the social and physical environment (i.e. interpersonal and community levels), the intrapersonal level is not comprehensively examined. For example, participants' knowledge of the importance of a healthful diet, self-efficacy to modify nutritional behavior, and perceived threats, benefits, and cues for action for adhering to healthful diet (components of the Health Belief Model) have been found to affect dietary intake and are not taken into account in the current study (National Cancer Institute 2005; Shaikh, Yaroch et al. 2008). Finally, the measures of dietary intake are derived from a validated instrument developed by the National Cancer Institute, but the instrument is only viewed as a screener for nutrition 
factors related to cancer and other health outcomes. A more comprehensive dietary questionnaire, such as the Food Frequency Questionnaire (Willett and Lenart 1998; Flagg, Coates et al. 2000) or biochemical markers of food consumption (Day, McKeown et al. 2001) might have provided a more accurate measure of dietary intake.

The association between proximity to healthy food sources (i.e. fresh food sources and pantries) and diet was smaller in magnitude and not statistically significant in the spatial models. However, the estimated magnitude of the association between proximity to fast food and diet was larger and more statistically significant in the spatial models. This may be because peer behavior is an important modifier of the relationship between the environment and dietary intake.

Results also suggest that perhaps chain grocery outlets (often the primary focus when considering access) might need to be considered along with an array of other food sources. Our measures of healthy food sources included a variety of different food sources commonly found in low-income communities: charitable pantries, chain grocers, and small, non-traditional food sources. Further, we found that proximity to the nearest fresh food source was positively related to whether or not participants listed a neighborhood food source as their primary or secondary grocery store. However, further work is needed to elucidate the causal nature of this correlative relationship since individuals sort into neighborhoods, and likewise commercial and non-profit food sources are purposefully located near prospective consumers.

Our findings pertaining to the role of proximity and social influences in determining dietary intake emphasize the need for policymakers and intervention designers to acknowledge the reciprocal relationship between people and place. Social marketing and education campaigns can be designed to address dietary norms, the types of foods provided by non-profit agencies, and peer behaviors. Our results suggest that these initiatives will be most effective if they are 
implemented to target specific geographic locations on multiple fronts to effectively address both the demand and supply of healthy foods.

Finally, study results highlight the potential role of geographic peer effects in individual nutrition behavior which is consistent with previous research finding a relationship between nutrition intake and social ties among African Americans (Yeh, Ickes et al. 2008; Zhylyevskyy, Jensen et al. 2012). While we modeled social influence as peer effects, our work was unable to distinguish direct peer-to-peer influences from social norms. Future studies should re-examine the endogenous relationship between peers' nutritional behavior using well-defined social network data (rather than geographic proximity). Behavioral economists might additionally focus on understanding the external validity of peer effects on nutritional behavior across different preferences for time and risk—factors which have been shown to impact obesity related outcomes/behaviors (Lusk and Coble 2005; Anderson and Mellor 2008; Richards and Hamilton 2012). Additionally, future behavioral interventions may be designed to produce an exogenous change in nutrition behavior that leverages and facilitates measurement of social multiplier effects in peers' nutrition outcomes.

Funding: This study was funded by the National Science Foundation (NSF/SES-0827350). 


\section{References}

Health Impact Assessment (HIA). The Determinants of Health. W. H. O. (WHO).

Akerlof, G. A. (1997). "Social distance and social decisions." Econometrica: Journal of the Econometric Society: $1005-1027$.

An, R. and R. Sturm (2012). "School and Residential Neighborhood Food Environment and Diet Among California Youth." American Journal of Preventive Medicine 42(2): 129-135.

Anderson, L. R. and J. M. Mellor (2008). "Predicting health behaviors with an experimental measure of risk preference." Journal of Health Economics 27(5): 1260-1274.

Anselin, L. (1988). Spatial Econometrics: Methods and Models, Kluwer Academic Publishers.

Azar, O. H. (2004). "What sustains social norms and how they evolve?: The case of tipping." Journal of Economic Behavior \& Organization 54(1): 49-64.

Block, G., B. Patterson, et al. (1992). "Fruit, vegetables, and cancer prevention: A review of the epidemiological evidence." Nutrition and Cancer 18(1): 1-29.

Bramoulle, Y., H. Djebbari, et al. (2009). "Identification of peer effects through social networks." Journal of Econometrics 150(1): 41-55.

Burdette, H. L. and R. C. Whitaker (2004). "Neighborhood playgrounds, fast food restaurants, and crime: relationships to overweight in low-income preschool children." Preventive Medicine 38(1): 5763.

Chen, S., R. J. G. M. Florax, et al. (2010). "Obesity and Access to Chain Grocers." Economic Geography 86(4): 431-452.

Chiteji, N. (2010). "Time-preference, Non-cognitive Skills and Well-being across the Life Course: Do Noncognitive Skills Encourage Healthy Behavior?" The American Economic Review 100(2): 200.

Christakis, N. A. and J. H. Fowler (2007). "The Spread of Obesity in a Large Social Network over 32 Years." New England Journal of Medicine 357(4): 370-379.

Cohen-Cole, E. and J. M. Fletcher (2008). "Detecting implausible social network effects in acne, height, and headaches: longitudinal analysis." BMJ: British Medical Journal 337.

Cohen-Cole, E. and J. M. Fletcher (2008). "Is obesity contagious? Social networks vs. environmental factors in the obesity epidemic." Journal of Health Economics 27(5): 1382-1387.

Corrado, L. and B. Fingleton (2012). "Where is the economics in spatial econometrics? ." Journal of Regional Science 52(2): 210-239.

Corrado, L. and B. Fingleton (2012). "WHERE IS THE ECONOMICS IN SPATIAL ECONOMETRICS?*." Journal of Regional Science 52(2): 210-239.

Davezies, L., X. D'Haultfoeuille, et al. (2009). "Identification of peer effects using group size variation." Econometrics Journal 12(3): 397-413.

Day, N. E., N. McKeown, et al. (2001). "Epidemiological assessment of diet: a comparison of a 7-day diary with a food frequency questionnaire using urinary markers of nitrogen, potassium and sodium." International Journal of Epidemiology 30(2): 309-317.

Dietz, R. D. (2002). "The estimation of neighborhood effects in the social sciences: An interdisciplinary approach." Social Science Research 31(4): 539-575.

Do, D. P., T. Dubowitz, et al. (2007). "Neighborhood context and ethnicity differences in body mass index: a multilevel analysis using the NHANES III survey (1988,Äi1994)." Economics \& Human Biology 5(2): 179-203.

Durlauf, S. N. (2004). "Neighborhood effects." Handbook of regional and urban economics 4: 2173-2242.

Durlauf, S. N. and Y. M. Ioannides (2010). "Social interactions." Annu. Rev. Econ. 2(1): 451-478.

Eisenberg, D. and B. C. Quinn (2006). "Estimating the Effect of Smoking Cessation on Weight Gain: An Instrumental Variable Approach." Health Services Research 41(6): 2255-2266. 
Elster, J. (1989). "Social norms and economic theory." The Journal of Economic Perspectives 3(4): 99117.

Finkelstein, E. A., K. L. Strombotne, et al. (2010). "The Costs of Obesity and Implications for Policymakers." Choices 25(3).

Flagg, E. W., R. J. Coates, et al. (2000). "Validation of the American Cancer Society Cancer Prevention Study II Nutrition Survey Cohort Food Frequency Questionnaire." Epidemiology 11(4).

Florax, R. J. G. M., H. Folmer, et al. (2003). "Specification searches in spatial econometrics: the relevance of Hendry, Äôs methodology." Regional Science and Urban Economics 33(5): 557-579.

Getz, G. S. and C. A. Reardon (2007). "Nutrition and Cardiovascular Disease." Arteriosclerosis, Thrombosis, and Vascular Biology 27(12): 2499-2506.

Gibbons, S. and H. G. Overman (2012). "MOSTLY POINTLESS SPATIAL ECONOMETRICS?*." Journal of Regional Science 52(2): 172-191.

Glanz, K., M. Basil, et al. (1998). "Why Americans Eat What They Do: Taste, Nutrition, Cost, Convenience, and Weight Control Concerns as Influences on Food Consumption." Journal of the American Dietetic Association 98(10): 1118-1126.

Grossman, M. (1972). "On the concept of health capital and the demand for health." The journal of political economy 80(2): 223-255.

Grossman, M. (2000). "The human capital model." Handbook of health economics 1: 347-408.

Habyarimana, J., M. Humphreys, et al. (2007). "Why Does Ethnic Diversity Undermine Public Goods Provision?" American Political Science Review 101(04): 709-725.

Hill, J. O. (2006). "Understanding and Addressing the Epidemic of Obesity: An Energy Balance Perspective." Endocrine Reviews 27(7): 750-761.

Hung, H.-C., K. J. Joshipura, et al. (2004). "Fruit and vegetable intake and risk of major chronic disease." Journal of the National Cancer Institute 96(21): 1577-1584.

Huston, S. J. and M. S. Finke (2003). "Diet choice and the role of time preference." Journal of Consumer Affairs 37(1): 143-160.

Ichiro, K., K. Daniel, et al. (2004). "Commentary: Reconciling the three accounts of social capital." International Journal of Epidemiology 33(4): 682-690.

loannides, Y. (2012). From Neighborhoods to Nations-The Economics of Social Interactions, Princeton University Press.

Jung, S., D. Spiegelman, et al. (2013). "Fruit and Vegetable intake and risk of Breast cancer by Hormone receptor Status." Journal of the National Cancer Institute 105(3): 219-236.

Kallbekken, S., H. Westskog, et al. (2010). "Appeals to social norms as policy instruments to address consumption externalities." The Journal of Socio-Economics 39(4): 447-454.

Keane, C. R., J. M. Lafky, et al. (2012). "Altruism, reciprocity and health: A social experiment in restaurant choice." Food Policy 37(2): 143-150.

Lee, L. (2007). "Identification and estimation of econometric models with group interactions, contextual factors and fixed effects." Journal of Econometrics 140(2): 333-374.

LeSage, J. (2012). "Econometrics Toolbox." Retrieved March 25, 2012, from http://www.spatialeconometrics.com/.

LeSage, J. and R. K. Pace (2009). Introduction to Spatial Econometrics, CRC Press/Taylor \& Francis Group.

Lopez-Perez, R. (2009). "Followers and leaders: Reciprocity, social norms and group behavior." The Journal of Socio-Economics 38(4): 557-567.

Lusk, J. L. and K. H. Coble (2005). "Risk perceptions, risk preference, and acceptance of risky food." American Journal of Agricultural Economics 87(2): 393-405.

Lyons, R. (2011). "The spread of evidence-poor medicine via flawed social-network analysis." Statistics, Politics, and Policy 2(1). 
Maddock, J. (2004). "The relationship between obesity and the prevalence of fast food restaurants: state-level analysis." American journal of health promotion : AJHP 19(2): 137-143.

Manski, C. F. (1993). "Identification of endogenous social effects: The reflection problem." The review of economic studies 60(3): 531-542.

Moore, K., A. V. D. Roux, et al. (2013). "Home and work neighbourhood environments in relation to body mass index: the Multi-Ethnic Study of Atherosclerosis (MESA)." Journal of Epidemiology and Community Health.

Moore, L. V., A. V. Diez Roux, et al. (2008). "Associations of the Local Food Environment with Diet Quality,ÄîA Comparison of Assessments based on Surveys and Geographic Information Systems." American Journal of Epidemiology 167(8): 917-924.

Morland, K., A. V. Diez Roux, et al. (2006). "Supermarkets, Other Food Stores, and Obesity: The Atherosclerosis Risk in Communities Study." American Journal of Preventive Medicine 30(4): 333-339.

Morland, K. B. and K. R. Evenson (2009). "Obesity prevalence and the local food environment." Health \& Place 15(2): 491-495.

Naik, N. Y. and M. J. Moore (1996). "Habit Formation and Intertemporal Substitution in Individual Food Consumption." The Review of Economics and Statistics 78(2): 321-328.

National Cancer Institute (2005). A Guide For Health Promotion Practice. Theory at A Glance. Washington, DC, National Institutes of Health.

Noel, H. and B. Nyhan (2011). "The, Äúunfriending,Äù problem: The consequences of homophily in friendship retention for causal estimates of social influence." Social Networks 33(3): 211-218.

Partridge, M. D., M. Boarnet, et al. (2012). "Introduction: Whither Spatial Econometrics?" Journal of Regional Science 52(2): 167-171.

Patrick, H. and T. A. Nicklas (2005). "A Review of Family and Social Determinants of Children,Äôs Eating Patterns and Diet Quality." Journal of the American College of Nutrition 24(2): 83-92.

Richards, T. J. and S. F. Hamilton (2012). "Obesity and Hyperbolic Discounting: An Experimental Analysis." Journal of Agricultural and Resource Economics 37(2): 181.

Sainsbury, P. (2008). "Commentary: Understanding social network analysis." BMJ 337.

Satija, A. and F. B. Hu (2012). "Cardiovascular Benefits of Dietary Fiber." Current Atherosclerosis Reports 14(6): 505-514.

Shaikh, A. R., A. L. Yaroch, et al. (2008). "Psychosocial predictors of fruit and vegetable consumption in adults: A review of the literature." American Journal of Preventive Medicine 34(6): 535-543. e511.

Shalizi, C. R. and A. C. Thomas (2011). "Homophily and contagion are generically confounded in observational social network studies." Sociological Methods \& Research 40(2): 211-239.

Simmons, D., A. McKenzie, et al. (2005). "Choice and availability of takeaway and restaurant food is not related to the prevalence of adult obesity in rural communities in Australia." Int J Obes Relat Metab Disord 29(6): 703-710.

Starr, M. A. (2009). "The social economics of ethical consumption: Theoretical considerations and empirical evidence." The Journal of Socio-Economics 38(6): 916-925.

Threapleton, D. E., D. C. Greenwood, et al. (2013). "Dietary Fiber Intake and Risk of First Stroke A Systematic Review and Meta-Analysis." Stroke 44(5): 1360-1368.

Tobler, W. R. (1970). "A computer movie simulating urban growth in the Detroit region." Economic Geography 46: 234-240.

Turrell, G. (1996). "Structural, material and economic influences on the food-purchasing choices of socioeconomic groups." Australian and New Zealand Journal of Public Health 20(6): 611-617. 
Turrell, G. and A. M. Kavanagh (2005). "Socio-economic pathways to diet: modelling the association between socio-economic position and food purchasing behaviour." Public Health Nutrition 9(3):

8.

US House of Representatives Select Committee on Hunger (1987). Obtaining Food: Shopping constraints on the Poor. Washington, DC, US Government Printing Office.

US House of Representatives Select Committee on Hunger (1992). Urban Grocery Gap. Washington, DC, US Government Printing Office: 20-21.

Ver Ploeg, M., V. Breneman, et al. (2009). Access to Affordable and Nutritious Food--Measuring and Understanding Food Desserts and Their Consequences: Report to Congress. E. R. Service: 160.

Viswanath, K. and K. Bond (2007). "Social Determinants and Nutrition: Reflections on the Role of Communication." Journal of Nutrition Education and Behavior 39(2, Supplement): S2O-S24.

Viswanath, K. W. R. J. J. R. (2006). "Social Capital and Health: Civic Engagement, Community Size, and Recall of Health Messages." American Journal of Public Health 96(8): 1456-1461.

Wada, R. and E. Tekin (2010). "Body composition and wages." Economics \& Human Biology 8(2): 242254.

Walker, R. E., C. R. Keane, et al. (2010). "Disparities and access to healthy food in the United States: a review of food deserts literature." Health \& Place 16(5): 876-884.

Wang, L., J. E. Manson, et al. (2012). "Fruit and vegetable intake and the risk of hypertension in middleaged and older women." American journal of hypertension 25(2): 180-189.

Wang, M. C., S. Kim, et al. (2007). "Socioeconomic and food-related physical characteristics of the neighbourhood environment are associated with body mass index." Journal of Epidemiology and Community Health 61(6): 491-498.

Wen, M. and T. N. Maloney (2013). "Neighborhood socioeconomic status and BMI differences by immigrant and legal status: Evidence from Utah." Economics \& Human Biology.

Willett, W. and E. Lenart, Eds. (1998). Reproducibility and validity of food-frequency questionnaires. Nutritional Epidemiology. Oxford, United Kingdom, Oxford University Press.

World Health Organization. (2013). "Obesity and overweight fact sheet." Retrieved March 17, 2014, 2014, from http://www.who.int/mediacentre/factsheets/fs311/en/.

Yeh, M.-C., S. B. Ickes, et al. (2008). "Understanding barriers and facilitators of fruit and vegetable consumption among a diverse multi-ethnic population in the USA." $\underline{\text { Health Promotion }}$ International 23(1): 42-51.

Zhen, C., M. K. Wohlgenant, et al. (2011). "Habit Formation and Demand for Sugar-Sweetened Beverages." American Journal of Agricultural Economics 93(1): 175-193.

Zhylyevskyy, O., H. H. Jensen, et al. (2012). "Effects of Family, Friends, and Relative Prices on Fruit and Vegetable Consumption by African Americans." Southern Economic Journal. 
Figure 1. Location of Survey Participants and Food Sources

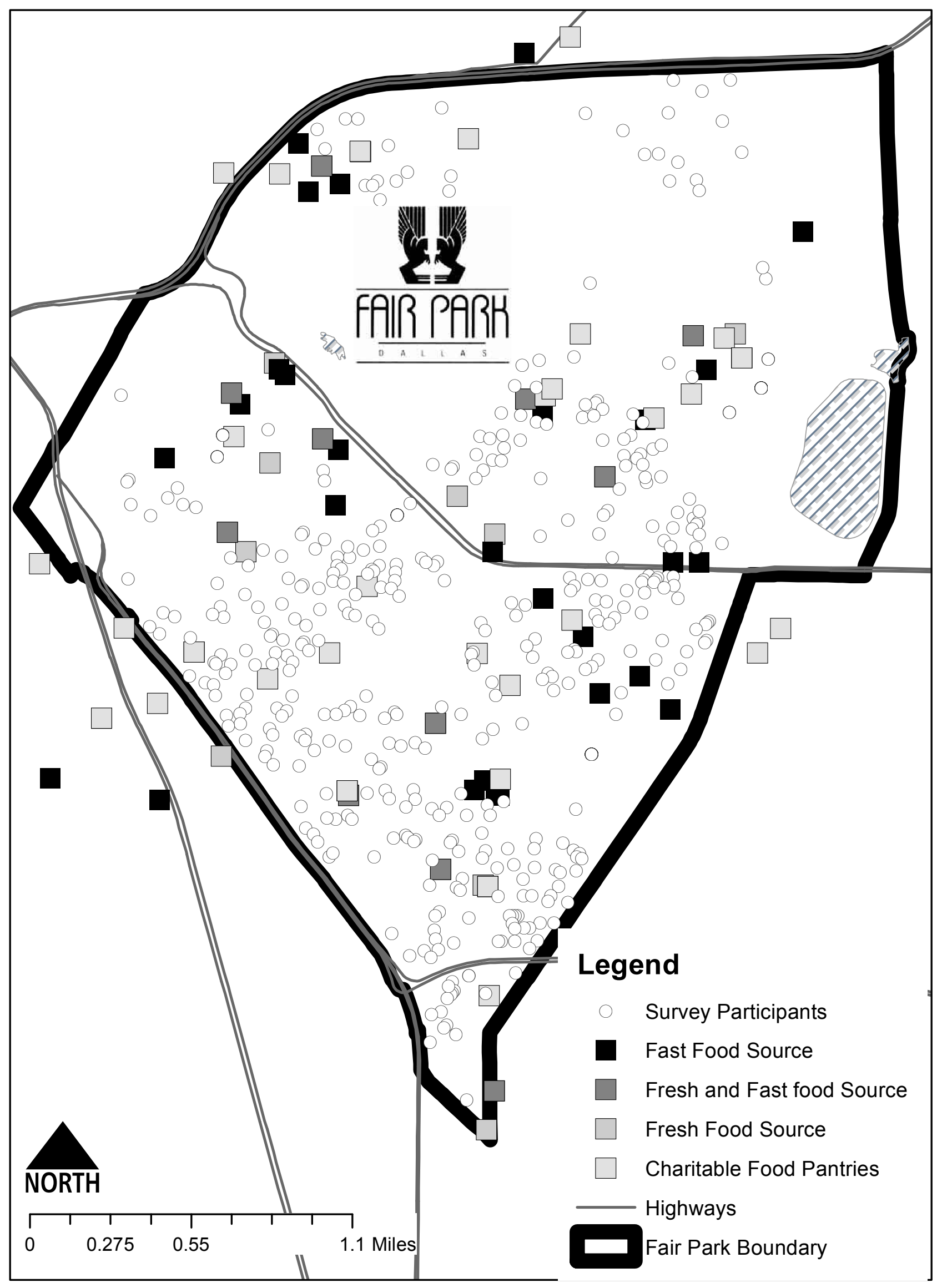


Table 1. Variable Deffinitions

\begin{tabular}{|c|c|}
\hline Variable & Description \\
\hline \multicolumn{2}{|l|}{ Dependent Variables } \\
\hline Fat & Variance adjusted percent calories obtained from fat \\
\hline Fruit \& Vegetables (no fries) & $\begin{array}{l}\text { Variance adjusted fruit and vegetable intake excluding fried potatoes } \\
\text { (pyramid servings) }\end{array}$ \\
\hline Fiber & Variance adjusted grams of fiber consumed \\
\hline \multicolumn{2}{|l|}{ Educational Attainment } \\
\hline Less than High School & Respondent did not complete a college degree or equivalent \\
\hline High School & Respondent has a high school degree or equivalent \\
\hline Some College & Respondent has completed at least some college courses \\
\hline \multicolumn{2}{|l|}{ Socio-Cultural Characteristics } \\
\hline Male & Respondent is male \\
\hline Age & Respondent's age \\
\hline Black & Respondent is African American \\
\hline Married & Respondent is married or living with a partner \\
\hline Kids & Respondent's household includes kids less than 18 years of age \\
\hline Underinsured & Respondent has inadquate health insurance \\
\hline Normal Weight & BMI is less than $25 \mathrm{~kg} / \mathrm{m}^{\wedge} 2$ \\
\hline Overweight & $\mathrm{BMI}$ is $25-29.9 \mathrm{~kg} / \mathrm{m}^{\wedge} 2$ \\
\hline Obese & $\mathrm{BMI}$ is $>29.9 \mathrm{~kg} / \mathrm{m}^{\wedge} 2$ \\
\hline Excellent Health & Self-reported health is excellent \\
\hline Very Good Health & Self-reported health is very good \\
\hline Good Health & Self-reported health is good \\
\hline Fair Health & Self-reported health is fair \\
\hline Poor Health & Self-reported health is poor \\
\hline \multicolumn{2}{|c|}{ Characteristics of the Social Environment } \\
\hline Friends Exercise & Many or all close friends and family exercise on a regular basis \\
\hline Friends in Neighborhood & Many or all close friends and family live in the neighborhood \\
\hline $\begin{array}{l}\text { Friends Exercise \& in } \\
\text { Neighborhood }\end{array}$ & $\begin{array}{l}\text { Interaction: Many or all close friends and family exercise and live in } \\
\text { neighborhood }\end{array}$ \\
\hline \multicolumn{2}{|c|}{ Characteristics of the Physical Environment } \\
\hline Distance to Fresh Food & Miles from home to the nearest neighborhood fresh food source \\
\hline Distance to Fast Food & Miles from home to the nearest fast food source \\
\hline Distance to Pantry & Miles from home to the nearest charitable food pantry \\
\hline Perceived Good Access & Agrees or strongly agrees neighborhood grocery stores are ad \\
\hline \multicolumn{2}{|c|}{ Characteristics of health input prices } \\
\hline Income $(<\$ 10,000)$ & Household income is less than $\$ 10,000$ \\
\hline Income $(\$ 10,000-\$ 20,000)$ & Household income is between $\$ 10,000$ and $\$ 20,000$ \\
\hline Income $(\$ 20,000-\$ 40,000)$ & Household income is between $\$ 20,000$ and $\$ 40,000$ \\
\hline Income $(>\$ 40,000)$ & Household income is greater than $\$ 40,000$ \\
\hline Food Budget & Monthly food expenditures divided by household size \\
\hline Don't Cook & Respondent typically prepares no meals at home \\
\hline Cook 1-5 Meals & Respondent typically prepares 1-5 meals per week at home \\
\hline Cook 6-10 Meals & Respondent typically prepares 6-10 meals per week at home \\
\hline Cook 11-15 Meals & Respondent typically prepares $11-15$ meals per week at home \\
\hline Cook 16-20 Meals & Respondent typically prepares $16-20$ meals per week at home \\
\hline Cook 20+ Meals & Respondent typically prepares more than 20 meals per week at home \\
\hline
\end{tabular}


Table 2. Summary Statistics for Variables Included in the Regression Models

\begin{tabular}{|c|c|c|c|c|}
\hline Variable & Mean & Standard Deviation & Minimum & Maximum \\
\hline \multicolumn{5}{|l|}{ Dependent Variables } \\
\hline Fat & 38.60 & 13.11 & 16.88 & 158.36 \\
\hline Fat-males & 37.70 & 6.32 & 30.58 & 66.76 \\
\hline Fat-females & 39.27 & 16.41 & 16.88 & 158.36 \\
\hline Fruit \& Vegetables (no fries) & 3.49 & 3.58 & 0.00 & 22.33 \\
\hline Fruit \& Vegetables (no fries)-males & 3.71 & 3.42 & 0.00 & 20.05 \\
\hline Fruit \& Vegetables (no fries)-females & 3.33 & 3.70 & 0.00 & 22.33 \\
\hline Fiber & 26.11 & 49.78 & 6.49 & 660.75 \\
\hline Fiber-males & 24.24 & 20.56 & 9.05 & 132.84 \\
\hline Fiber-females & 27.49 & 63.30 & 6.49 & 660.75 \\
\hline \multicolumn{5}{|l|}{ Educational Attainment } \\
\hline Less than High School & 0.23 & 0.42 & 0 & 1 \\
\hline High School & 0.40 & 0.49 & 0 & 1 \\
\hline Some College & 0.37 & 0.48 & 0 & 1 \\
\hline \multicolumn{5}{|l|}{ Socio-Cultural Characteristics } \\
\hline Male & 0.43 & 0.50 & 0 & 1 \\
\hline Age & 44.53 & 14.09 & 18 & 88 \\
\hline Black & 0.93 & 0.26 & 0 & 1 \\
\hline Married & 0.25 & 0.43 & 0 & 1 \\
\hline Kids & 0.47 & 0.50 & 0 & 1 \\
\hline Underinsured & 0.41 & 0.49 & 0 & 1 \\
\hline Normal Weight & 0.30 & 0.46 & 0 & 1 \\
\hline Overweight & 0.26 & 0.44 & 0 & 1 \\
\hline Obese & 0.44 & 0.50 & 0 & 1 \\
\hline Excellent Health & 0.10 & 0.30 & 0 & 1 \\
\hline Very Good Health & 0.25 & 0.43 & 0 & 1 \\
\hline Good Health & 0.36 & 0.48 & 0 & 1 \\
\hline Fair Health & 0.24 & 0.43 & 0 & 1 \\
\hline Poor Health & 0.05 & 0.21 & 0 & 1 \\
\hline \multicolumn{5}{|l|}{ Characteristics of the Social Environment } \\
\hline Friends Exercise & 0.29 & 0.46 & 0 & 1 \\
\hline Friends in Neighborhood & 0.44 & 0.50 & 0 & 1 \\
\hline Interaction: Friends Exercise \& Friends in Neighborhood & 0.14 & 0.35 & 0 & 1 \\
\hline \multicolumn{5}{|l|}{ Characteristics of the Physical Environment } \\
\hline Perceived Good Access & 0.37 & 0.48 & 0 & 1 \\
\hline Distance to Fresh Food (miles) & 0.24 & 0.15 & 0 & 0.84 \\
\hline Distance to Fast Food (miles) & 0.18 & 0.11 & 0 & 0.55 \\
\hline Distance to Pantry (miles) & 0.17 & 0.12 & 0 & 0.62 \\
\hline \multicolumn{5}{|l|}{ Characteristics of health input prices } \\
\hline Household Income $(<\$ 10,000)$ & 0.49 & 0.50 & 0 & 1 \\
\hline Household Income $(\$ 10,000-\$ 20,000)$ & 0.24 & 0.43 & 0 & 1 \\
\hline Household Income $(\$ 20,000-\$ 40,000)$ & 0.19 & 0.40 & 0 & 1 \\
\hline Household Income $(>\$ 40,000)$ & 0.15 & 0.35 & 0 & 1 \\
\hline Food Budget (\$/Month/person) & 136.25 & 117.76 & 0 & 800 \\
\hline Don't Cook & 0.07 & 0.25 & 0 & 1 \\
\hline Cook 1-5 Meals per week & 0.55 & 0.50 & 0 & 1 \\
\hline Cook 6-10 Meals per week & 0.17 & 0.38 & 0 & 1 \\
\hline Cook 11-15 Meals per week & 0.09 & 0.28 & 0 & 1 \\
\hline Cook 16-20 Meals per week & 0.06 & 0.24 & 0 & 1 \\
\hline Cook 20+ Meals per week & 0.06 & 0.24 & 0 & 1 \\
\hline
\end{tabular}


Table 3. OLS Estimation Results for Models of Food Consumption Measures ( $N=298$ )

\begin{tabular}{|c|c|c|c|}
\hline Dependent Variable: & $\begin{array}{c}\text { Fruits \& } \\
\text { Vegetables } \\
\text { Consumption }\end{array}$ & $\begin{array}{l}\text { \% Calories } \\
\text { from Fat }\end{array}$ & $\begin{array}{c}\text { Fiber } \\
\text { Consumption }\end{array}$ \\
\hline \multirow[t]{2}{*}{ Male } & 0.083 & -2.672 & -8.996 \\
\hline & $(0.120)$ & $(2.060)$ & $(8.362)$ \\
\hline \multirow[t]{2}{*}{ Age } & $-0.009 *$ & $-0.154^{*}$ & -0.251 \\
\hline & $(0.004)$ & $(0.069)$ & $(0.212)$ \\
\hline \multirow[t]{2}{*}{ High School } & -0.073 & -3.316 & -22.230 \\
\hline & $(0.158)$ & $(3.053)$ & $(19.070)$ \\
\hline \multirow[t]{2}{*}{ Some College } & -0.038 & -2.628 & -14.530 \\
\hline & $(0.152)$ & $(3.182)$ & $(16.510)$ \\
\hline \multirow[t]{2}{*}{ Black } & -0.082 & $13.21^{* *}$ & -0.121 \\
\hline & $(0.334)$ & $(4.857)$ & $(27.180)$ \\
\hline \multirow[t]{2}{*}{ Married } & -0.047 & -1.057 & 1.542 \\
\hline & $(0.135)$ & $(1.796)$ & $(7.434)$ \\
\hline \multirow[t]{2}{*}{ Kids } & 0.007 & -1.557 & -5.730 \\
\hline & $(0.131)$ & $(2.235)$ & $(6.381)$ \\
\hline \multirow[t]{2}{*}{ Household Income $(\$ 10,000-\$ 20,000)$} & 0.198 & $4.511^{*}$ & 21.110 \\
\hline & $(0.157)$ & $(2.030)$ & $(15.340)$ \\
\hline \multirow[t]{2}{*}{ Household Income $(\$ 20,000-\$ 40,000)$} & 0.083 & 6.523 & 15.590 \\
\hline & $(0.157)$ & $(4.089)$ & $(13.290)$ \\
\hline \multirow{2}{*}{ Household Income $(>\$ 40,000)$} & 0.190 & -1.621 & -2.007 \\
\hline & $(0.151)$ & $(2.389)$ & $(8.899)$ \\
\hline \multirow[t]{2}{*}{ Food Budget } & 0.001 & 0.011 & 0.056 \\
\hline & $(0.001)$ & $(0.010)$ & $(0.044)$ \\
\hline \multirow[t]{2}{*}{ Underinsured } & -0.183 & 0.438 & -7.589 \\
\hline & $(0.113)$ & $(1.987)$ & $(6.060)$ \\
\hline \multirow[t]{2}{*}{ Normal Weight } & $0.305^{*}$ & 3.651 & 6.651 \\
\hline & $(0.138)$ & $(2.282)$ & $(11.480)$ \\
\hline \multirow[t]{2}{*}{ Overweight } & $0.236+$ & 0.388 & -10.970 \\
\hline & $(0.140)$ & $(2.564)$ & $(12.570)$ \\
\hline \multirow[t]{2}{*}{ Excellent Health } & 0.111 & 4.889 & 19.810 \\
\hline & $(0.347)$ & $(7.533)$ & $(36.930)$ \\
\hline \multirow[t]{2}{*}{ Very Good Health } & -0.271 & $-7.821^{*}$ & -36.520 \\
\hline & $(0.281)$ & $(3.871)$ & $(22.740)$ \\
\hline \multirow[t]{2}{*}{ Good Health } & -0.253 & $-7.179+$ & -36.570 \\
\hline & $(0.289)$ & (3.949) & $(23.800)$ \\
\hline \multirow[t]{2}{*}{ Fair Health } & -0.194 & $-7.743+$ & -32.760 \\
\hline & $(0.284)$ & $(4.064)$ & $(22.970)$ \\
\hline \multirow[t]{2}{*}{ Perceived Good Access } & -0.019 & 3.463 & 9.481 \\
\hline & $(0.118)$ & $(2.165)$ & $(7.482)$ \\
\hline
\end{tabular}


Table 3 (Continued). OLS Estimation Results for Models of Food Consumption Measures ( $\mathrm{N}=\mathbf{2 9 8}$ )

\begin{tabular}{|c|c|c|c|}
\hline Dependent Variable: & $\begin{array}{c}\text { Fruits \& } \\
\text { Vegetables } \\
\text { Consumption }\end{array}$ & $\begin{array}{c}\text { \% Calories } \\
\text { from Fat }\end{array}$ & $\begin{array}{c}\text { Fiber } \\
\text { Consumption }\end{array}$ \\
\hline \multirow[t]{2}{*}{ Cook 1-5 Meals per week } & 0.388 & 3.241 & 7.973 \\
\hline & $(0.265)$ & $(3.320)$ & $(12.370)$ \\
\hline \multirow[t]{2}{*}{ Cook 6-10 Meals per week } & $0.614^{*}$ & 3.725 & 9.491 \\
\hline & $(0.281)$ & $(3.117)$ & $(12.450)$ \\
\hline \multirow[t]{2}{*}{ Cook 11-15 Meals per week } & 0.488 & 0.165 & 6.380 \\
\hline & $(0.297)$ & $(3.339)$ & $(13.710)$ \\
\hline \multirow[t]{2}{*}{ Cook $16-20$ Meals per week } & $0.619+$ & 8.177 & 58.490 \\
\hline & $(0.355)$ & $(6.181)$ & $(52.970)$ \\
\hline \multirow[t]{2}{*}{ Cook 20+ Meals per week } & $0.917^{*}$ & 14.240 & 59.570 \\
\hline & $(0.398)$ & $(8.754)$ & $(40.380)$ \\
\hline \multirow[t]{2}{*}{ Friends Exercise } & $0.324+$ & 1.825 & 3.375 \\
\hline & $(0.182)$ & $(2.142)$ & $(7.513)$ \\
\hline \multirow[t]{2}{*}{ Friends in Neighborhood } & 0.124 & $5.685^{*}$ & 8.649 \\
\hline & $(0.133)$ & $(2.486)$ & $(8.723)$ \\
\hline \multirow[t]{2}{*}{ Interaction: Friends Exercise \& Friends in Neighborhood } & -0.069 & -5.400 & 14.750 \\
\hline & $(0.263)$ & $(4.290)$ & $(25.500)$ \\
\hline \multirow[t]{2}{*}{ Distance to Fresh Food } & $-0.734^{*}$ & -4.688 & -22.250 \\
\hline & $(0.360)$ & $(8.381)$ & $(33.180)$ \\
\hline \multirow[t]{2}{*}{ Distance to Fast Food } & $0.948+$ & -2.048 & -6.493 \\
\hline & $(0.487)$ & $(8.138)$ & $(30.630)$ \\
\hline \multirow[t]{2}{*}{ Distance to Pantry } & -0.950 & 3.629 & 13.940 \\
\hline & $(0.584)$ & $(11.500)$ & $(48.680)$ \\
\hline \multirow[t]{2}{*}{ Constant } & $1.751^{* *}$ & $31.44 * * *$ & 57.980 \\
\hline & $(0.653)$ & $(8.765)$ & $(54.080)$ \\
\hline
\end{tabular}

$* * * p<0.001, * * p<0.01, * p<0.05,+p<0.10$

Robust standard errors are in parenthesis

Reference category for Household Income is $<\$ 10,000$; reference category for obesity variables is obese; reference category for health status is Poor Health; reference category for Cooking is 0 Meals per week. 
Table 4. Logistic Regression for Utilization of Neighborhood Fresh Food Sources ( $N=256)$

\begin{tabular}{|c|c|}
\hline Dependent Variable: & $\begin{array}{l}\text { Individual shops at a neighborhood fresh } \\
\text { food source }\end{array}$ \\
\hline \multirow[t]{2}{*}{ Distance to Fresh Food } & $-1.980 *$ \\
\hline & $(0.899)$ \\
\hline \multirow[t]{2}{*}{ Male } & 0.210 \\
\hline & $(0.290)$ \\
\hline \multirow[t]{2}{*}{ Age } & $0.0274^{*}$ \\
\hline & $(0.012)$ \\
\hline \multirow[t]{2}{*}{ High School } & -0.307 \\
\hline & $(0.378)$ \\
\hline \multirow[t]{2}{*}{ Some College } & -0.283 \\
\hline & $(0.397)$ \\
\hline \multirow[t]{2}{*}{ Black } & 0.566 \\
\hline & $(0.682)$ \\
\hline \multirow[t]{2}{*}{ Married } & 0.224 \\
\hline & $(0.345)$ \\
\hline \multirow[t]{2}{*}{ Kids } & 0.309 \\
\hline & $(0.318)$ \\
\hline \multirow[t]{2}{*}{ Household Income $(\$ 10,000-\$ 20,000)$} & -0.026 \\
\hline & $(0.347)$ \\
\hline \multirow[t]{2}{*}{ Household Income $(\$ 20,000-\$ 40,000)$} & -0.016 \\
\hline & $(0.387)$ \\
\hline \multirow{2}{*}{ Household Income $(>\$ 40,000)$} & 0.094 \\
\hline & $(0.428)$ \\
\hline \multirow[t]{2}{*}{ Food Budget } & 0.000 \\
\hline & $(0.001)$ \\
\hline \multirow[t]{2}{*}{ Underinsured } & 0.135 \\
\hline & $(0.286)$ \\
\hline \multirow[t]{2}{*}{ Normal Weight } & $-0.634+$ \\
\hline & $(0.351)$ \\
\hline \multirow[t]{2}{*}{ Overweight } & $-0.633+$ \\
\hline & $(0.349)$ \\
\hline \multirow[t]{2}{*}{ Excellent Health } & -0.584 \\
\hline & $(0.867)$ \\
\hline \multirow[t]{2}{*}{ Very Good Health } & -0.232 \\
\hline & $(0.803)$ \\
\hline \multirow[t]{2}{*}{ Good Health } & -0.534 \\
\hline & $(0.791)$ \\
\hline \multirow[t]{2}{*}{ Fair Health } & -0.563 \\
\hline & $(0.790)$ \\
\hline \multirow[t]{2}{*}{ Constant } & 0.040 \\
\hline & $(1.138)$ \\
\hline
\end{tabular}

Robust standard errors are in parenthesis

Reference category for Household Income is $<\$ 10,000$; reference category for obesity variables is obese; reference category for health status is Poor Health. 
Table 5. SAR Estimation Results (8NN) for Models of Food Consumption Measures ( $N=298)$

\begin{tabular}{|c|c|c|c|}
\hline Dependent Variable: & $\begin{array}{c}\text { Fruits \& } \\
\text { Vegetables } \\
\text { Consumption }\end{array}$ & $\begin{array}{l}\% \text { Calories } \\
\text { from Fat }\end{array}$ & $\begin{array}{c}\text { Fiber } \\
\text { Consumption }\end{array}$ \\
\hline \multirow[t]{2}{*}{ Rho } & $0.175^{*}$ & 0.079 & -0.008 \\
\hline & $(0.084)$ & $(0.084)$ & $(0.097)$ \\
\hline \multirow[t]{2}{*}{ Male } & 0.111 & -2.286 & -8.499 \\
\hline & $(0.112)$ & $(1.914)$ & $(8.435)$ \\
\hline \multirow[t]{2}{*}{ Age } & -0.004 & -0.053 & -0.031 \\
\hline & $(0.004)$ & $(0.071)$ & $(0.308)$ \\
\hline \multirow[t]{2}{*}{ High School } & -0.017 & -2.048 & $-19.975+$ \\
\hline & $(0.143)$ & $(2.458)$ & $(10.826)$ \\
\hline \multirow[t]{2}{*}{ Some College } & 0.027 & -1.424 & -12.427 \\
\hline & $(0.151)$ & $(2.580)$ & $(11.363)$ \\
\hline \multirow[t]{2}{*}{ Black } & 0.255 & $19.971^{* * *}$ & 13.722 \\
\hline & $(0.240)$ & (4.173) & $(18.035)$ \\
\hline \multirow[t]{2}{*}{ Married } & -0.052 & -1.004 & 1.528 \\
\hline & $(0.134)$ & $(2.296)$ & $(10.121)$ \\
\hline \multirow[t]{2}{*}{ Kids } & 0.092 & 0.177 & -2.062 \\
\hline & $(0.120)$ & $(2.063)$ & $(9.052)$ \\
\hline \multirow[t]{2}{*}{ Household Income $(\$ 10,000-\$ 20,000)$} & 0.162 & $4.086+$ & $20.387^{*}$ \\
\hline & $(0.135)$ & $(2.307)$ & $(10.167)$ \\
\hline \multirow[t]{2}{*}{ Household Income $(\$ 20,000-\$ 40,000)$} & 0.083 & $6.604^{* *}$ & 15.789 \\
\hline & $(0.149)$ & $(2.557)$ & $(11.272)$ \\
\hline \multirow[t]{2}{*}{ Household Income $(>\$ 40,000)$} & 0.195 & -1.224 & -1.445 \\
\hline & $(0.173)$ & $(2.972)$ & $(13.098)$ \\
\hline \multirow[t]{2}{*}{ Food Budget } & 0.001 & $0.014+$ & $0.061+$ \\
\hline & $(0.001)$ & $(0.008)$ & $(0.036)$ \\
\hline \multirow[t]{2}{*}{ Underinsured } & -0.155 & 1.087 & -6.295 \\
\hline & $(0.111)$ & $(1.895)$ & $(8.351)$ \\
\hline \multirow[t]{2}{*}{ Normal Weight } & $0.379 * *$ & $5.285^{*}$ & 10.308 \\
\hline & $(0.130)$ & $(2.239)$ & $(9.816)$ \\
\hline \multirow[t]{2}{*}{ Overweight } & $0.248+$ & 0.740 & -10.096 \\
\hline & $(0.134)$ & $(2.305)$ & $(10.151)$ \\
\hline \multirow[t]{2}{*}{ Excellent Health } & 0.430 & $10.722^{*}$ & 32.049 \\
\hline & $(0.295)$ & $(5.091)$ & $(22.179)$ \\
\hline \multirow[t]{2}{*}{ Very Good Health } & 0.042 & -2.118 & -24.464 \\
\hline & $(0.265)$ & $(4.558)$ & $(19.834)$ \\
\hline \multirow[t]{2}{*}{ Good Health } & 0.070 & -1.298 & -24.297 \\
\hline & $(0.256)$ & $(4.397)$ & $(19.120)$ \\
\hline \multirow[t]{2}{*}{ Fair Health } & 0.097 & -2.446 & -21.654 \\
\hline & $(0.262)$ & $(4.509)$ & $(19.672)$ \\
\hline \multirow[t]{2}{*}{ Perceived Good Access } & 0.031 & $4.526^{*}$ & 11.898 \\
\hline & $(0.115)$ & $(1.977)$ & (8.681) \\
\hline
\end{tabular}


Table 5 (Continued). SAR Estimation Results (8NN) for Models of Food Consumption Measures (N=298)

\begin{tabular}{|c|c|c|c|}
\hline Dependent Variable: & $\begin{array}{c}\text { Fruits \& } \\
\text { Vegetables } \\
\text { Consumption }\end{array}$ & $\begin{array}{c}\text { \% Calories } \\
\text { from Fat }\end{array}$ & $\begin{array}{c}\text { Fiber } \\
\text { Consumption }\end{array}$ \\
\hline \multirow[t]{2}{*}{ Cook 1-5 Meals per week } & $0.614^{* *}$ & $7.753^{*}$ & 17.853 \\
\hline & $(0.209)$ & $(3.594)$ & $(15.644)$ \\
\hline \multirow[t]{2}{*}{ Cook 6-10 Meals per week } & $0.847 * * *$ & $8.470 *$ & 19.633 \\
\hline & $(0.228)$ & (3.918) & $(17.114)$ \\
\hline \multirow[t]{2}{*}{ Cook 11-15 Meals per week } & $0.727^{* *}$ & 5.048 & 17.300 \\
\hline & $(0.259)$ & $(4.450)$ & $(19.466)$ \\
\hline \multirow[t]{2}{*}{ Cook 16-20 Meals per week } & $0.800 * *$ & $11.962^{*}$ & $66.784 * *$ \\
\hline & $(0.299)$ & $(5.131)$ & $(22.549)$ \\
\hline \multirow[t]{2}{*}{ Cook 20+ Meals per week } & $1.196 * * *$ & $20.023 * * *$ & $72.327 * * *$ \\
\hline & $(0.288)$ & $(4.961)$ & $(21.604)$ \\
\hline \multirow[t]{2}{*}{ Friends Exercise } & $0.392 *$ & 3.151 & 5.831 \\
\hline & $(0.164)$ & $(2.807)$ & $(12.367)$ \\
\hline \multirow[t]{2}{*}{ Friends in Neighborhood } & 0.217 & $7.528^{* * *}$ & 11.938 \\
\hline & $(0.133)$ & $(2.277)$ & $(10.014)$ \\
\hline \multirow[t]{2}{*}{ Interaction: Friends Exercise \& Friends in Neighborhood } & -0.109 & -6.035 & 13.883 \\
\hline & $(0.240)$ & (4.119) & $(18.149)$ \\
\hline \multirow[t]{2}{*}{ Distance to Fresh Food } & -0.554 & -3.834 & -19.341 \\
\hline & $(0.377)$ & $(6.444)$ & $(28.414)$ \\
\hline \multirow[t]{2}{*}{ Distance to Fast Food } & $1.047^{*}$ & 3.302 & 1.544 \\
\hline & $(0.498)$ & $(8.451)$ & $(37.242)$ \\
\hline \multirow[t]{2}{*}{ Distance to Pantry } & -0.481 & 11.433 & 26.708 \\
\hline & $(0.512)$ & $(8.784)$ & $(38.652)$ \\
\hline
\end{tabular}

$* * * p<0.001, * * p<0.01, * p<0.05,+p<0.10$

Robust standard errors are in parenthesis

Reference category for Household Income is $<\$ 10,000$; reference category for obesity variables is obese; reference category for health status is Poor Health; reference category for Cooking is 0 Meals per week. 
Table 6. Instrumental Variables Estimation for Geographic Peer Effects on Fruits and Vegetables Consumption ( $\mathrm{N}=\mathbf{2 9 8}$ )

\begin{tabular}{|c|c|c|c|}
\hline & Model 1 & Model 2 & Model 3 \\
\hline Dependent Variable: & \multicolumn{3}{|c|}{ Fruits and Vegetables Consumption } \\
\hline Instruments: & $\begin{array}{c}\text { All } \\
\text { Instruments }\end{array}$ & $\begin{array}{c}\text { Variables } \\
\text { related to } \\
\text { People }\end{array}$ & $\begin{array}{c}\text { Variables } \\
\text { related to } \\
\text { Place } \\
\end{array}$ \\
\hline \multirow[t]{2}{*}{ Rho } & $0.679 * * *$ & $0.640 * *$ & 0.502 \\
\hline & $(0.203)$ & $(0.220)$ & $(0.392)$ \\
\hline \multirow[t]{2}{*}{ Male } & 0.142 & 0.138 & 0.126 \\
\hline & $(0.118)$ & $(0.117)$ & $(0.117)$ \\
\hline \multirow[t]{2}{*}{ Age } & $-0.00893^{*}$ & $-0.00894^{*}$ & $-0.00897^{*}$ \\
\hline & $(0.004)$ & $(0.004)$ & $(0.004)$ \\
\hline \multirow[t]{2}{*}{ High School } & -0.069 & -0.069 & -0.070 \\
\hline & $(0.152)$ & $(0.151)$ & $(0.150)$ \\
\hline \multirow[t]{2}{*}{ Some College } & 0.014 & 0.011 & 0.000 \\
\hline & $(0.150)$ & $(0.150)$ & $(0.149)$ \\
\hline \multirow{2}{*}{ Black } & -0.057 & -0.059 & -0.0636 \\
\hline & $(0.294)$ & $(0.294)$ & $(0.298)$ \\
\hline \multirow[t]{2}{*}{ Married } & -0.065 & -0.064 & -0.060 \\
\hline & $(0.133)$ & $(0.133)$ & $(0.131)$ \\
\hline \multirow[t]{2}{*}{ Kids } & 0.001 & 0.001 & 0.002 \\
\hline & $(0.128)$ & $(0.127)$ & $(0.125)$ \\
\hline \multirow[t]{2}{*}{ Household Income $(\$ 10,000-\$ 20,000)$} & 0.134 & 0.138 & 0.1510 \\
\hline & $(0.148)$ & $(0.147)$ & $(0.153)$ \\
\hline \multirow[t]{2}{*}{ Household Income $(\$ 20,000-\$ 40,000)$} & 0.061 & 0.062 & 0.0666 \\
\hline & $(0.156)$ & $(0.155)$ & $(0.155)$ \\
\hline \multirow[t]{2}{*}{ Household Income $(>\$ 40,000)$} & 0.157 & 0.158 & 0.165 \\
\hline & $(0.147)$ & $(0.147)$ & $(0.146)$ \\
\hline \multirow[t]{2}{*}{ Food Budget } & 0.001 & 0.001 & 0.0005 \\
\hline & $(0.001)$ & $(0.001)$ & $(0.001)$ \\
\hline \multirow[t]{2}{*}{ Underinsured } & $-0.196+$ & $-0.195+$ & $-0.193+$ \\
\hline & $(0.108)$ & $(0.108)$ & $(0.107)$ \\
\hline \multirow[t]{2}{*}{ Normal Weight } & $0.256+$ & $0.259+$ & $0.269 *$ \\
\hline & $(0.133)$ & $(0.133)$ & $(0.133)$ \\
\hline \multirow[t]{2}{*}{ Overweight } & 0.2070 & 0.2090 & 0.215 \\
\hline & $(0.135)$ & $(0.135)$ & $(0.134)$ \\
\hline \multirow[t]{2}{*}{ Excellent Health } & 0.213 & 0.207 & 0.1860 \\
\hline & $(0.330)$ & $(0.329)$ & $(0.328)$ \\
\hline \multirow[t]{2}{*}{ Very Good Health } & -0.169 & -0.175 & -0.195 \\
\hline & $(0.272)$ & $(0.271)$ & $(0.271)$ \\
\hline \multirow{2}{*}{ Good Health } & -0.135 & -0.142 & -0.166 \\
\hline & $(0.275)$ & $(0.275)$ & $(0.275)$ \\
\hline \multirow[t]{2}{*}{ Fair Health } & -0.092 & -0.098 & -0.118 \\
\hline & $(0.271)$ & $(0.270)$ & $(0.267)$ \\
\hline \multirow[t]{2}{*}{ Perceived Good Access } & -0.045 & -0.044 & -0.0384 \\
\hline & $(0.117)$ & $(0.116)$ & $(0.115)$ \\
\hline
\end{tabular}


Table 6 (Continued). Instrumental Variables Estimation for Geographic Peer Effects on Fruits and Vegetables Consumption ( $\mathrm{N}=\mathbf{2 9 8}$ )

\begin{tabular}{|c|c|c|c|}
\hline & Model 1 & Model 2 & Model 3 \\
\hline Dependent Variable: & \multicolumn{3}{|c|}{ Fruits and Vegetables Consumption } \\
\hline Instruments: & $\begin{array}{c}\text { All } \\
\text { Instruments }\end{array}$ & $\begin{array}{c}\text { Variables } \\
\text { related to } \\
\text { People }\end{array}$ & $\begin{array}{c}\text { Variables } \\
\text { related to } \\
\text { Place }\end{array}$ \\
\hline \multirow[t]{2}{*}{ Cook 1-5 Meals per week } & 0.3550 & 0.3570 & 0.3640 \\
\hline & $(0.244)$ & $(0.244)$ & $(0.245)$ \\
\hline \multirow[t]{2}{*}{ Cook 6-10 Meals per week } & $0.583^{*}$ & $0.585^{*}$ & $0.591^{*}$ \\
\hline & $(0.262)$ & $(0.262)$ & $(0.262)$ \\
\hline \multirow[t]{2}{*}{ Cook 11-15 Meals per week } & 0.4290 & 0.4320 & 0.444 \\
\hline & $(0.266)$ & $(0.266)$ & $(0.271)$ \\
\hline \multirow[t]{2}{*}{ Cook 16-20 Meals per week } & 0.5610 & $0.565+$ & $0.576+$ \\
\hline & $(0.343)$ & $(0.341)$ & $(0.341)$ \\
\hline \multirow[t]{2}{*}{ Cook 20+ Meals per week } & $0.820 *$ & $0.826^{*}$ & $0.846 *$ \\
\hline & $(0.380)$ & $(0.378)$ & $(0.384)$ \\
\hline \multirow[t]{2}{*}{ Friends Exercise } & $0.357^{*}$ & $0.355^{*}$ & $0.349+$ \\
\hline & $(0.180)$ & $(0.179)$ & $(0.179)$ \\
\hline \multirow[t]{2}{*}{ Friends in Neighborhood } & 0.176 & 0.173 & 0.1620 \\
\hline & $(0.127)$ & $(0.126)$ & $(0.129)$ \\
\hline \multirow[t]{2}{*}{ Interaction: Friends Exercise \& Friends in Neighborhood } & -0.146 & -0.141 & -0.126 \\
\hline & $(0.259)$ & $(0.258)$ & $(0.259)$ \\
\hline \multirow[t]{2}{*}{ Distance to Fresh Food } & -0.317 & -0.341 & -0.426 \\
\hline & $(0.356)$ & $(0.354)$ & $(0.416)$ \\
\hline \multirow[t]{2}{*}{ Distance to Fast Food } & 0.5760 & 0.5980 & 0.673 \\
\hline & $(0.468)$ & $(0.469)$ & $(0.487)$ \\
\hline \multirow[t]{2}{*}{ Distance to Pantry } & -0.328 & -0.364 & -0.490 \\
\hline & $(0.590)$ & $(0.600)$ & $(0.658)$ \\
\hline \multirow[t]{2}{*}{ Constant } & 0.347 & 0.428 & 0.713 \\
\hline & $(0.705)$ & $(0.729)$ & $(1.012)$ \\
\hline R-squared & 0.128 & 0.135 & 0.154 \\
\hline
\end{tabular}

Robust standard errors are in parenthesis

Reference category for Household Income is $<\$ 10,000$; reference category for obesity variables is obese; reference category for health status is Poor Health; reference category for Cooking is 0 Meals per week.

Instruments for Model 1 are the spatially lagged values of Male, Age, High School, Some College, Black, Married, Kids, Income $(\$ 10,000-\$ 20,000)$, Income $(\$ 20,000-\$ 40,000)$, Income $(>\$ 40,000)$, Food Budget, Underinsured, Normal Weight, Overweight, Excellent Health, Very Good Health, Good Health, Fair Health, Perceived Good access, Cook 1-5 Meals, Cook 11-15 Meals, Cook 16-20 Meals, Cook 20+ Meals, Friends Exercise, Friends in Neighborhood, Interaction: Friends Exercise \& Friends in Neighborhood, Distance to Fresh Food, Distance to Fast Food, Distance to Pantry.

Instruments for Model 2 are the spatially lagged values of Male, Age, High School, Some College, Black, Married, Kids, Income (\$10,000-\$20,000), Income (\$20,000-\$40,000), Income (>\$40,000), Food Budget, Underinsured, Normal Weight, Overweight, Excellent Health, Very Good Health, Good Health, Fair Health, Cook 1-5 Meals, Cook 11-15 Meals, Cook 16-20 Meals, Cook 20+ Meals, Friends Exercise, Friends in Neighborhood, Interaction: Friends Exercise \& Friends in Neighborhood

Instruments for Model 3 are the spatially lagged values of Perceived Good access, Distance to Fresh Food, Distance to Fast Food, Distance to Pantry. 
Table 7. Instrumental Variables Estimation for Geographic Peer Effects on Fruit and Vegetable Consumption

\begin{tabular}{|c|c|c|c|c|}
\hline & Model 4 & Model 5 & Model 6 & Model 7 \\
\hline Instruments: & \multicolumn{4}{|c|}{ Variables related to People } \\
\hline Dependent Variable: & \multicolumn{4}{|c|}{ Fruits and Vegetables Consumption } \\
\hline Sample: & $\begin{array}{l}\text { Individuals } \\
\text { living in } \\
\text { areas where } \\
\text { people talk } \\
\text { to each } \\
\text { other } \\
(\mathrm{N}=118)\end{array}$ & \begin{tabular}{|c|} 
Individuals \\
living in \\
areas where \\
people do \\
not talk to \\
others \\
$(\mathrm{N}=112)$
\end{tabular} & \begin{tabular}{|} 
Individuals \\
living in \\
areas where \\
people help \\
each other \\
$(\mathrm{N}=123)$
\end{tabular} & $\begin{array}{l}\text { Individuals } \\
\text { living in } \\
\text { areas where } \\
\text { people do } \\
\text { not help } \\
\text { (N=119) }\end{array}$ \\
\hline \multirow[t]{2}{*}{ Rho } & $0.715^{*}$ & 0.545 & $0.738 * *$ & 0.385 \\
\hline & $(0.326)$ & $(0.340)$ & $(0.247)$ & $(0.301)$ \\
\hline \multirow[t]{2}{*}{ Male } & 0.107 & $0.384^{*}$ & -0.019 & 0.156 \\
\hline & $(0.183)$ & $(0.180)$ & $(0.225)$ & $(0.143)$ \\
\hline \multirow[t]{2}{*}{ Age } & $-0.0127+$ & -0.009 & 0.001 & $-0.00986^{*}$ \\
\hline & $(0.007)$ & $(0.005)$ & $(0.007)$ & $(0.004)$ \\
\hline \multirow[t]{2}{*}{ High School } & -0.225 & 0.261 & 0.112 & -0.110 \\
\hline & $(0.274)$ & $(0.206)$ & $(0.239)$ & $(0.170)$ \\
\hline \multirow[t]{2}{*}{ Some College } & 0.015 & 0.212 & -0.074 & 0.232 \\
\hline & $(0.280)$ & $(0.190)$ & $(0.250)$ & $(0.218)$ \\
\hline \multirow[t]{2}{*}{ Black } & -0.1650 & $-1.014+$ & -0.3510 & 0.2650 \\
\hline & $(0.459)$ & $(0.532)$ & $(0.339)$ & $(0.346)$ \\
\hline \multirow[t]{2}{*}{ Married } & -0.112 & 0.019 & $0.538^{*}$ & $-0.286+$ \\
\hline & $(0.235)$ & $(0.189)$ & $(0.230)$ & $(0.166)$ \\
\hline \multirow[t]{2}{*}{ Kids } & -0.164 & -0.055 & 0.151 & 0.036 \\
\hline & $(0.240)$ & $(0.196)$ & $(0.282)$ & $(0.160)$ \\
\hline \multirow[t]{2}{*}{ Household Income $(\$ 10,000-\$ 20,000)$} & -0.1210 & $0.543^{*}$ & -0.1720 & 0.2830 \\
\hline & $(0.244)$ & $(0.216)$ & $(0.223)$ & $(0.210)$ \\
\hline \multirow[t]{2}{*}{ Household Income $(\$ 20,000-\$ 40,000)$} & 0.0727 & -0.0486 & -0.0965 & 0.1320 \\
\hline & $(0.251)$ & $(0.194)$ & $(0.411)$ & $(0.176)$ \\
\hline \multirow[t]{2}{*}{ Household Income $(>\$ 40,000)$} & 0.041 & $0.450^{*}$ & 0.657 & 0.072 \\
\hline & $(0.292)$ & $(0.214)$ & $(0.424)$ & $(0.194)$ \\
\hline \multirow[t]{2}{*}{ Food Budget } & 0.0001 & -0.0005 & -0.0006 & $0.00144+$ \\
\hline & $(0.001)$ & $(0.001)$ & $(0.001)$ & $(0.001)$ \\
\hline \multirow[t]{2}{*}{ Underinsured } & $-0.395+$ & -0.113 & -0.247 & -0.145 \\
\hline & $(0.205)$ & $(0.149)$ & $(0.183)$ & $(0.151)$ \\
\hline \multirow[t]{2}{*}{ Normal Weight } & 0.1310 & $0.382+$ & $0.438^{*}$ & 0.1620 \\
\hline & $(0.229)$ & $(0.214)$ & $(0.223)$ & $(0.195)$ \\
\hline \multirow[t]{2}{*}{ Overweight } & 0.193 & 0.279 & 0.265 & 0.018 \\
\hline & $(0.243)$ & $(0.190)$ & $(0.247)$ & $(0.185)$ \\
\hline \multirow[t]{2}{*}{ Excellent Health } & -0.0896 & -0.3850 & 0.0133 & $1.120^{*}$ \\
\hline & $(0.700)$ & $(0.394)$ & (0.511) & $(0.564)$ \\
\hline \multirow[t]{2}{*}{ Very Good Health } & -0.629 & -0.265 & -0.255 & 0.441 \\
\hline & $(0.536)$ & $(0.257)$ & $(0.348)$ & $(0.389)$ \\
\hline \multirow[t]{2}{*}{ Good Health } & -0.723 & 0.104 & 0.114 & 0.353 \\
\hline & $(0.517)$ & $(0.180)$ & $(0.318)$ & $(0.400)$ \\
\hline \multirow[t]{2}{*}{ Fair Health } & -0.601 & -0.031 & -0.170 & 0.647 \\
\hline & $(0.523)$ & $(0.180)$ & $(0.331)$ & $(0.444)$ \\
\hline \multirow[t]{2}{*}{ Perceived Good Access } & 0.2000 & $-0.377^{*}$ & 0.1680 & -0.2340 \\
\hline & $(0.238)$ & $(0.171)$ & $(0.182)$ & $(0.143)$ \\
\hline
\end{tabular}


Table 7 (Continued). Instrumental Variables Estimation for Geographic Peer Effects on Fruit and Vegetable Consumption

\begin{tabular}{|c|c|c|c|c|}
\hline & Model 4 & Model 5 & Model 6 & Model 7 \\
\hline Instruments: & \multicolumn{4}{|c|}{ Variables related to People } \\
\hline Dependent Variable: & \multicolumn{4}{|c|}{ Fruits and Vegetables Consumption } \\
\hline Sample: & \begin{tabular}{|c|} 
Individuals \\
living in \\
areas where \\
people talk \\
to each \\
other \\
$(\mathrm{N}=118)$ \\
\end{tabular} & \begin{tabular}{|c} 
Individuals \\
living in \\
areas where \\
people do \\
not talk to \\
others \\
$(\mathrm{N}=112)$ \\
\end{tabular} & $\begin{array}{l}\text { Individuals } \\
\text { living in } \\
\text { areas where } \\
\text { people help } \\
\text { each other } \\
(\mathrm{N}=123)\end{array}$ & $\begin{array}{l}\text { Individuals } \\
\text { living in } \\
\text { areas where } \\
\text { people do } \\
\text { not help } \\
\text { (N=119) }\end{array}$ \\
\hline \multirow[t]{2}{*}{ Cook 1-5 Meals per week } & 0.6520 & 0.1680 & 0.1870 & $0.722 * *$ \\
\hline & $(0.462)$ & $(0.393)$ & $(0.521)$ & $(0.228)$ \\
\hline \multirow[t]{2}{*}{ Cook 6-10 Meals per week } & 0.6060 & $0.766^{*}$ & 0.2350 & $1.195^{* * *}$ \\
\hline & $(0.541)$ & $(0.379)$ & $(0.492)$ & $(0.281)$ \\
\hline \multirow[t]{2}{*}{ Cook 11-15 Meals per week } & 0.571 & -0.117 & 0.121 & $0.892 * *$ \\
\hline & $(0.486)$ & $(0.405)$ & $(0.594)$ & $(0.288)$ \\
\hline \multirow[t]{2}{*}{ Cook 16-20 Meals per week } & $1.068+$ & -0.0505 & -0.1520 & $1.362^{* * *}$ \\
\hline & $(0.575)$ & $(0.439)$ & $(0.597)$ & $(0.400)$ \\
\hline \multirow[t]{2}{*}{ Cook $20+$ Meals per week } & $1.255+$ & -0.2570 & 0.6380 & $1.145^{* *}$ \\
\hline & $(0.666)$ & $(0.543)$ & $(0.662)$ & $(0.441)$ \\
\hline \multirow[t]{2}{*}{ Friends Exercise } & $0.588+$ & -0.099 & -0.126 & $0.476^{*}$ \\
\hline & $(0.325)$ & $(0.295)$ & $(0.284)$ & $(0.228)$ \\
\hline \multirow[t]{2}{*}{ Friends in Neighborhood } & 0.1040 & -0.0229 & 0.3060 & 0.3100 \\
\hline & $(0.228)$ & $(0.167)$ & $(0.236)$ & $(0.190)$ \\
\hline \multirow[t]{2}{*}{ Interaction: Friends Exercise \& Friends in Neighborhood } & 0.070 & 0.041 & 0.071 & 0.111 \\
\hline & $(0.449)$ & $(0.363)$ & $(0.387)$ & $(0.389)$ \\
\hline \multirow[t]{2}{*}{ Distance to Fresh Food } & 0.096 & 0.606 & 0.590 & $-1.130^{*}$ \\
\hline & $(0.814)$ & $(0.471)$ & $(0.670)$ & $(0.545)$ \\
\hline \multirow[t]{2}{*}{ Distance to Fast Food } & 0.910 & -0.155 & 0.357 & 0.961 \\
\hline & $(0.970)$ & $(0.691)$ & $(0.767)$ & $(0.765)$ \\
\hline \multirow[t]{2}{*}{ Distance to Pantry } & 0.269 & $-1.148^{*}$ & -0.449 & 0.800 \\
\hline & $(1.097)$ & $(0.583)$ & $(0.920)$ & $(0.797)$ \\
\hline \multirow[t]{2}{*}{ Constant } & 0.913 & $1.509+$ & $(0.008)$ & $(0.683)$ \\
\hline & $(1.318)$ & $(0.862)$ & $(0.926)$ & $(0.921)$ \\
\hline
\end{tabular}

R-squared

0.242

0.338

0.215

0.366

$* * * p<0.001, * * p<0.01, * p<0.05,+p<0.10$

Robust standard errors are in parenthesis

Reference category for Household Income is $<\$ 10,000$; reference category for obesity variables is obese; reference category for health status is Poor Health; reference category for Cooking is 0 Meals per week.

Instruments are the spatially lagged values of Male, Age, High School, Some College, Black, Married, Kids, Income (\$10,000-\$20,000), Income (\$20,000-\$40,000), Income (>\$40,000), Food Budget, Underinsured, Normal Weight, Overweight, Excellent Health, Very Good Health, Good Health, Fair Health, Cook 1-5 Meals, Cook 11-15 Meals, Cook 16-20 Meals, Cook 20+ Meals, Friends Exercise, Friends in Neighborhood, Interaction: Friends Exercise \& Friends in Neighborhood. 